\title{
Reflexiones en torno a la relación entre memoria y política
}

\author{
Notes on the relation of memory and politics
}

Enviado em: 13/03/2017

Aceito em: 04/06/07

SAN JULIÁN, Dolores ${ }^{1}$

\begin{abstract}
Resumen:
En este ensayo nos aproximamos a la relación entre memoria y política desde una perspectiva que resalta el carácter contingente de todo orden social, y por tanto también, de todo régimen de memoria. En primer lugar, se exploran algunas definiciones que se han construido en torno a la política, y lo político como una dimensión diferente de aquélla, a partir de las ideas vertidas sobre el tema desde la filosofía y la ciencia política contemporánea. Luego, se trabaja sobre el concepto de memoria, subrayando su aspecto conflictivo para, desde allí, analizar las modalidades que asume su relación con la política y con lo político. Finalmente, se proponen una serie de reflexiones sobre cómo pensar la articulación entre memoria y política en el marco de las disputas por los sentidos asignados sobre el pasado reciente en Argentina.
\end{abstract}

Palabras clave: memoria, política, pasado reciente

\begin{abstract}
:
In this essay we analyze the relation between memory and politics, from a perspective that highlights the contingent character of any social organization and,therefore, of any memorial system. Firstly, we explore some definitions that have been establishedregarding
\end{abstract}

\footnotetext{
${ }^{1}$ Antropóloga. Docente, becaria doctoral y doctoranda en antropología (UBA). Miembro del equipo UBACyT "Lugares y políticas de la memoria" (IIGEO-FFyL-UBA) y del grupo "Lugares, marcas y territorios de la memoria" (Núcleo de Estudios sobre Memoria-IDES).
} 
politics as a different dimension within the fields of Philosophy and Political Science. Secondly, we examine the concept of memory, emphasizing its controversial aspects and analyzing its relation with the political realm. Finally, we examine the articulation between memory and politicswithin the disputes around the meanings attributed to the recent past in Argentina.

Key words: memory, politics, recent past

\section{Introducción}

La distinción conceptual entre la política y lo político ha provocado un cambio radical en la perspectiva filosófica sobre este campo, en tanto implica reconocer el carácter histórico de todo orden político social y la ausencia de un fundamento último que justifique una u otra forma de organización. Lo político, como dimensión presente en toda sociedad, hace referencia a aquello que desborda y muestra la contingencia de las distintas configuraciones que asumen la sociedad y la política en diversos contextos históricos (GORDILLO, 2012).

Esta diferenciación conceptual, vale decir, es deudora de la definición del estatuto de lo político dada tempranamente por el teórico alemán Carl Schmitt (2009). Para este autor, lo político no define un campo específico de la realidad (como veremos sí lo hace la política) sino cierto estado de tensión alcanzado por las relaciones sociales. Así, una oposición de cualquier clase (cultural, religiosa, económica, etc.) se transforma en antagonismo político en la medida en que adquiere la fuerza suficiente para agrupar a los sujetos implicados en amigos y enemigos. Lo político, entonces, no se reduce al campo de las prácticas estatales o de la competencia intraestatal entre partidos (aún cuando los antagonismos políticos tengan lugar dentro de la unidad política y territorial definida por el Estado), toda vez que Estado y sociedad no se oponen entre sí sino que se interpenetran 


\section{Memória}

recíprocamente. ${ }^{2}$ En este sentido, para el autor todo es potencialmente político, o mejor dicho, toda acción o relación social puede volverse política.

Autores contemporáneos, provenientes tanto del campo de la ciencia política como de la filosofía (A. Badiou, J. Rancière $y$ otros), han propuesto diversas conceptualizaciones sobre lo político y la política, otorgándole mayor consistencia teórica a esa distinción que asomaba en el pensamiento de Schmitt. En términos generales y, aún con alternancias en el uso de los términos, para estos autores la política refiere al orden en el cual predomina el aparato estatal como instancia normalizadora de la vida social (GORDILLO, 2012), mientras que lo político se presenta como una dimensión ontológica de la sociedad, que excede el campo de la política convencional y, en última instancia, la funda.

Siguiendo estos lineamientos teóricos, en este trabajo analizamos la relación entre memoria y política, desde una perspectiva que resalta el carácter contingente de todo orden social, y por tanto también, de toda figura o régimen de memoria. En primer lugar, exploramos algunas definiciones que se han construido en torno a la política y lo político, a partir de las ideas vertidas sobre el tema desde los campos de la filosofía y la ciencia política. Luego, abordamos el concepto de memoria subrayando su aspecto conflictivo para, desde allí, analizar las modalidades que asume su relación con la política y con lo político. Finalmente, proponemos una serie de reflexiones sobre cómo pensar la articulación entre memoria y política en el marco de las disputas por los sentidos asignados al pasado reciente en Argentina.

\section{Lo político y la política: una aproximación teórica}

\footnotetext{
2 Para Schmitt (2009) la democracia moderna se caracteriza por no contar con ámbitos "neutrales", en el sentido de no estatales y no políticos, como el pensamiento liberal afirma respecto de la economía. Para el autor, Estado y sociedad civil se interpelan mutuamente y ello implica que no existen instancias meramente sociales o exclusivamente estatales.
} 
Si toda relación o acción es potencialmente política, en el sentido apuntado por Schmitt, para otros autores la distinción última entre amigos y enemigos es sólo una de las formas -la más extrema- que puede asumir el vínculo social. Retomando críticamente las ideas del filósofo alemán, Chantal Mouffe sostiene que lo político refiere al modo mismo en que se instituye la sociedad, a una dimensión conflictual que es constitutiva de la vida social y, por tanto, irreductible e inerradicable. La política, por su parte, consiste en el conjunto de prácticas e instituciones a través de las cuales se crea un determinado orden social, que permite organizar (y asegurar) la coexistencia humana "en el contexto de la conflictividad derivada de lo político" (MOUFFE, 2007, p. 16). Dado este polo de conflictividad latente, podemos decir que todo orden hegemónico es siempre inestable y contingente, abierto a desplazamientos y renegociaciones constantes.

Admitiendo, entonces, la posibilidad siempre presente del antagonismo, es posible pensar en otros modos de expresión política del conflicto que no pongan en peligro a la sociedad, en tanto y en cuanto el "ellos" no se perciba como enemigo sino como adversario político. ${ }^{3}$ Para Mouffe, el modelo adversarial permite a la política democrática transformar el antagonismo en agonismo, una forma de relación social que, si bien conflictiva, previene mejor que otras la resolución violenta de los conflictos, porque en ella los actores se reconocen mutuamente legítimos y a la vez parte de un espacio simbólico común. Así, el antagonismo no es eliminado sino doblegado, gracias a la existencia de canales políticos para la expresión del disenso.

En la vereda opuesta al pensamiento liberal, para autores como Mouffe o Claude Lefort, la existencia del conflicto no atenta contra la democracia sino que es, justamente, lo que la garantiza. ${ }^{4}$ El ejercicio efectivo de aquélla no necesita reconciliar todos los intereses o valores en disputa, requiere, por el contrario, asegurar la existencia de una esfera pública de lucha agonista, donde puedan confrontarse diferentes proyectos

\footnotetext{
${ }^{3}$ Para Mouffe (2007) las relaciones nosotros/ellos se encuentran presentes en toda sociedad, como formas colectivas de identificación hacia afuera de la misma y al interior de ella. Siguiendo a Schmitt, sostiene que la relación amigo/enemigo, como un tipo de relación nosotros/ellos, puede surgir a partir de formas muy diversas de relaciones sociales, siempre y cuando éstas adquieran la tensión suficiente para alcanzar el grado extremo de distinción que implica que el "ellos" se percibe como amenaza a la propia identidad y, por tanto también, a la propia existencia.

${ }^{4}$ Aquí los autores discuten con una corriente del pensamiento político liberal (de tipo "deliberativo") que propone la eliminación del conflicto en la sociedad y su reemplazo por una política consensual "racional" e inclusiva, basada en la libre discusión.
} 


\section{memória}

hegemónicos (MOUFFE, 2007). La institucionalización del conflicto político a través de un poder des-incorporado, sujeto a la competencia entre sujetos y grupos por ocupar transitoriamente el poder del Estado (LEFORT, 1990) permite, en última instancia, legitimar el conflicto existente en la sociedad. ${ }^{5}$ Sin embargo, éste debe hallar su solución simbólica en la esfera política, de otro modo, la democracia corre el riesgo de engendrar en su seno formaciones totalitarias, como modo de conjurar la división social. Para Lefort, entonces, este modo de acceso y ejercicio del poder político implica que la sociedad moderna carece de un fundamento estable, es decir, que se enfrenta una y otra vez con la incerteza.

Esta forma de pensar en un orden político de lo instituido y en una dimensión política instituyente ${ }^{6}$, la encontramos también en el pensamiento de autores como Alain Badiou y Jacques Rancière. En ¿Se puede pensar la política? (2007) Badiou inviertelos significados dados a esos términos en tanto para él lo político designa la práctica política convencional mientras que la política define un movimiento que interrumpe la normalidad instituida, dando lugar a aquello que no estaba previsto. Ese momento instituyente de la política es, en última instancia, lo que prueba la inexistencia de un fundamento último del orden social y nos señala que las cosas siempre "podrían ser de otro modo".

Por un lado, el autor concibe lo político como mera representación, como "expresión programática" de intereses e ideologías en conflicto en el seno de la sociedad. Lo político, entendido como ficción, supone que los diversos grupos políticos "representan" diferentes colectivos sociales, pugnan por tomar el poder del Estado para concretar sus demandas, o bien intentan proyectarlas en él y en la sociedad a través de la negociación de políticas públicas. El Estado constituye, pues, su máxima expresión, como

\footnotetext{
${ }^{5}$ Para Lefort la democracia moderna se caracteriza por el advenimiento del poder político como un lugar "vacío", esto es, como una forma de poder que no puede ser in-corporado, apropiado de modo permanente por ninguna persona. De esta manera, el poder no se tiene, simplemente se ejerce o no se ejerce. En palabras del autor, en tanto el poder permanece como un lugar vacío, "conserva la impronta del conflicto político que revela ser constitutivo de su ejercicio, es decir, la impronta de la división" (LEFORT, 1990, p. 190). ${ }^{6}$ Si hablamos de lo instituido y lo instituyente ello nos remite directamente al pensamiento de Cornelius Castoriadis. Para este autor (1993) lo social instituido se corresponde con las estructuras dadas mientras que lo social instituyente es lo que irrumpe y estructura, lo que trabaja para transformar lo instituido. Pero este trabajo apunta inmediatamente a un resultado, que es darse de nuevo una institución para existir en ella de manera visible. En efecto, para Castoriadis lo social sólo se puede presentar en y por las instituciones. La sociedad no puede darse algo por fuera de lo simbólico, pero lo social es siempre e infinitamente algo más que la institución, dado que es justamente lo que la crea, la mantiene, la altera o la destruye.
} 


\section{memória}

estructura que ordena la realidad y la custodia. Por el contrario, la "verdadera política" es para Badiou un movimiento que irrumpe en el espacio de lo instituido y lo trastoca. Es un momento disruptivo e iluminador que tiene consecuencias, en tanto da lugar a la novedad política. Así, la política existe por fuera del Estado, porque justamente viene a alterar el ordenamiento que éste garantiza. Se presenta siempre como exceso, como desborde, sobre el Estado, la sociedad civil y sus instituciones. Dada su esencia no programática, la imagen militante de la política implica la presencia de actores políticos in mediación. La política no consiste, pues, en representar a los sujetos sino en ser fiel a los acontecimientos en que éstos se pronuncian e implica asumir los riesgos que conlleva la posibilidad de modificar lo instituido.

En una perspectiva semejante, Rancière (1996) sostiene que la política es la expresión de un desacuerdo, no en torno a contenidos particulares que hacen a la vida en común, sino a la posibilidad misma de expresar esas demandas, de ser tenido en-cuenta como interlocutor, por el Estado y por la sociedad. La política adviene entonces cuando una parte cualquiera de los in-contados reclama para sí ese reconocimiento, necesario y anterior a toda participación en un debate político concreto. Se trata de una primera dimensión del conflicto, diferente de aquél que se desarrolla dentro de los espacios habilitados - o los lugares disponibles (GROSSBERG, 1992) - para la expresión del disenso. La política es lo que permite marcar rupturas y reordenar o sustituir esa distribución de cuerpos, lugares, funciones y voces reconocibles dentro de la sociedad en un momento histórico particular, para dar paso a nueva configuración social. La política es, entonces, una intervención sobre lo visible y lo enunciable, sobre aquello que Rancière (2006) llama la "policía", esto es, un cierto "reparto de lo sensible", una ley social implícita que define las formas y condiciones del ser "parte de" la comunidad y por lo mismo de ser visto y escuchado. ${ }^{7}$

El desacuerdo se expresa, entonces, sobre la situación de habla misma, sobre los que cuentan y no cuentan dentro de "la comunidad de seres parlantes". Emerge cuando los sujetos cuya voz no es reconocida como tal, cuyos enunciados no pueden ser

\footnotetext{
${ }^{7}$ Aquí nos encontramos nuevamente con una modificación en el uso de los términos, puesto que lo que antes llamábamos "política", en el sentido de prácticas políticas convencionales, Rancière lo denomina policía, reservando el primer término para la actividad que viene a desestructurarla.
} 


\section{W Memória}

percibidos más que como ruido, reclaman para sí tener un lenguaje articulado. Toman a su cargo esta distorsión y le dan una figura, inventan nuevas formas de expresión política y se dan sus propios nombres. Al igual que Badiou, para Rancière la política propone un escenario en el cual "las partes no preexisten al conflicto que nombran y en el cual se hacen contar [primero y ante todo] como partes" (RANCIÈRE, 1996, p. 41, los corchetes son nuestros). No se trata de la expresión de un conflicto de intereses $u$ opiniones entre sujetos y/o grupos previamente constituidos, sino que los que instauran el litigios e constituyen como actores políticos en el mismo proceso. En el camino mucho de lo nuevo se pierde, queda fuera o es traducido en los términos de la hegemonía, mientras otro tanto logra incorporarse y producir transformaciones siquiera mínimas en el orden vigente.

En síntesis, más allá del lenguaje empleado y de los aspectos que cada autor enfatiza, en términos generales definen a la política como el campo en el cual prevalecen las prácticas estatales y la competencia entre partidos y asociaciones de distinto tipo; donde los conflictos se expresan a través de canales estables y habilitados para el disenso, en los cuales algunos grupos y sujetos participan, mientras otros se mantienen (o son mantenidos) por fuera. Proponen, por el contrario, pensar lo político como una dimensión conflictiva radical, constitutiva de la sociedad, cuya presencia latente e inerradicable es la condición misma de posibilidad para que emerja algo nuevo, para que se produzca un movimiento que altere, reconfigure o bien sustituya el ordenamiento vigente. En última instancia, lo que se intenta resaltar es la relación entre lo instituido y lo instituyente. Si la política se transforma, si los lugares y objetos de la política se actualizan, es justamente porque toma contacto con lo político, con la experiencia que busca abrirse espacio en ella, que produce fisuras e instaura - o vuelve visibles- nuevas prácticas y pensamientos.

\section{La memoria y la(0) política(o)}

Analizar la relación de la memoria con la política y, por extensión, con lo político, requiere algunas consideraciones previas. Sin adentrarnos en detalle en las múltiples 


\section{Memória}

discusiones desarrolladas dentro del campo de estudios sobre memoria social respecto a su objeto de estudio, consideramos necesario explicitar primero y ante todo a qué nos referimos cuando hablamos de memoria. Un supuesto fuerte es aquél que pone el acento en la dimensión colectiva de la misma, entendiéndola de un modo amplio como la práctica social de "traer el pasado al presente" (RAMOS, 2011). Halbwachs (2004) es en este sentido una referencia ineludible al postular tempranamente que la memoria individual se encuentra socialmente atravesada, constituida a través de imágenes, ideas 0 pensamientos acerca del pasado que son compartidos por un grupo y que operan como marco social de referencia para el recuerdo individual. Si bien niega la posibilidad de una memoria individual autónoma, proponiendo una inevitable interpenetración con su dimensión social, no desconoce el carácter diverso, plural y heterogéneo que asumen los recuerdos. Las memorias autobiográficas se constituyen así en un punto de vista sobre la memoria colectiva, en tanto se apropian de manera diferencial de las percepciones e impresiones comunes sobre el pasado (RAMOS, 2011), manteniendo una suerte de "negociación" con éstas.

Autores como Bastide (1970) y Pollak (2006), entre otros, han propuesto reelaboraciones sobre los desarrollos teóricos de Halbwachs, explicitando aquello que en su obra ya se esbozaba: el carácter potencialmente conflictivo de la memoria. En este sentido Pollak habla de un "trabajo de encuadramiento" de la misma, definiendo así el proceso por el cual algunas memorias logran formalizarse en el interior de un grupo o sociedad, mientras que otras, indecibles y/o con menos recursos para imponerse, continúan transmitiéndose en forma subterránea hasta que una coyuntura favorable posibilite su expresión pública. Lejos entonces de pensarla como necesariamente continua y estable, en este tipo de abordajes el foco está puesto en analizar los modos en que la memoria se vuelve objeto de disputas entre actores que pugnan por establecer, convencer y transmitir al resto del grupo o sociedad una determinada narrativa sobre el pasado (JELIN, 2002).

Partiendo entonces de una definición de memoria que enfatiza su carácter procesual, abierto a tensiones y conflictos, proponemos pensar su relación con el campo 


\section{memória}

de la política y con la dimensión delo político. ${ }^{8} \mathrm{~A}$ tal efecto, proponemos distinguir analíticamente al menos dos modalidades de esta relación que en la práctica se presentan mutuamente imbricadas. Podemos decir, en todo caso, que se trata de distintas dimensiones o aspectos de una misma relación. En primer lugar, la memoria constituye una práctica política, entendida en los términos de acciones y discursos orientados o bien a sostener en el tiempo un orden social dado, o bien a transformarlo. Sobre la base de un pasado compartido o proyectado como tal, la memoria, entre otros elementos que intervienen en la lucha hegemónica, permite construir legitimidades y sentidos de pertenencia ligados a grupos y proyectos políticos en pugna. Esta perspectiva, frecuentemente asociada a la idea de un "uso político del pasado", conlleva sin embargo algunos riesgos: por un lado, el problema de enfatizar excesivamente en las determinaciones del presente y el aspecto instrumental de la memoria, descuidando así su vínculo con el pasado ${ }^{9}$; por el otro, el error de abordar del mismo modo las memorias de quienes experimentan las relaciones de dominación desde diferentes posiciones sociales (RAMOS, 2011). No hace falta insistir en que no todos los grupos y sujetos cuentan con las mismas posibilidades de construir y transmitir públicamente sus memorias. En un sentido más radical, la memoria es política no sólo porque participa en acciones hegemónicas y contra hegemónicas sino porque que ella misma constituye un motor de la política, tiene un valor político en cuanto es capaz de generar representaciones y símbolos que movilicen políticamente a los actores sociales (FELD, 2016).

Ahora bien, si la memoria se encuentra ligada a identidades políticas, ello implica que la práctica de "traer el pasado al presente" puede dar lugar a diversos modos de relación nosotros/ellos. En el límite, puede promover, justificar y legitimar agrupamientos construidos en el sentido amigo/enemigo (SCHMITT,2009). La memoria puede entonces asumir formas violentas de expresión. Tal es el caso de aquellos grupos, incluyendo los que ocupan el poder del Estado, cuyas memorias se sostienen en la negación y/o el silenciamiento de otras, percibidas como una amenaza a su propia identidad y a sus

\footnotetext{
${ }^{8}$ Aquí retomaremos algunas de las conceptualizaciones ofrecidas en la sección anterior en torno a lo político y la política. A los fines de mantener una claridad expositiva no nos detendremos en las variaciones terminológicas empleadas por los autores.

${ }^{9}$ Lo que conduce, en el extremo, a entender la memoria como pura invención, como simple estrategia política o interpretación siempre tendenciosa.
} 


\section{memom roda}

proyectos políticos; como también el caso de quienes explotan un pasado de sufrimientos para justificar su poder, privilegios y sojuzgamiento sobre otros grupos en el presente, situaciones que Todorov (2008) concebía como un "abuso de la memoria". Siguiendo a Schmitt podríamos pensar que la memoria adquiere un sentido político en la medida en que promueve el agrupamiento de los actores en juego en términos de amigos y enemigos. Sin embargo, los conflictos entre identidades y memorias no siempre, ni necesariamente, se plantean en términos antagónicos, también suelen asumir una forma "agonista", es decir, adversarial. Como ya hemos señalado, para Mouffe (2007) y Lefort (1990) la vigencia de un marco político democrático depende de la existencia de canales abiertos para el disenso y el conflicto. Esto incluye la posibilidad de que proyectos hegemónicos opuestos o alternativos encuentren un espacio de expresión y discusión pública, así como también las memorias sobre las que eventualmente se sostienen.

Una segunda modalidad de la relación entre memoria y política es aquella en la cual la memoria se convierte en objeto de la política y de lo político. Vale decir que, respecto de lo anterior, más que un tipo de vínculo distinto, de lo que se trata es de un desplazamiento del foco de atención. En esta forma de articular los conceptos el acento ya no está puesto en la memoria como práctica sobre la que se sostienen-en el sentido de que legitima o moviliza- determinados proyectos políticos, sino en la memoria como objeto de prácticas políticas. Aquí la memoria no es tanto un elemento que interviene en las luchas políticas sino el punto de referencia mismo de los conflictos. Así, por un lado, la memoria se convierte en objeto de "políticas" orientadas a la rememoración y conmemoración de determinados acontecimientos. En ese proceso diversos actores políticos pugnan porque sus lecturas sobre el pasado encuentren un espacio de "expresión programática" (BADIOU, 2007) en el Estado, o bien buscan proyectarlas al conjunto de la sociedad a través de sus propias acciones e instituciones. Cabe recordar aquí, retomando a Schmitt (2009), que Estado y sociedad se interpenetran recíprocamente y, en este sentido, el campo de la memoria no pertenece exclusivamente a ninguno de los dos, sino que en él se encuentran e interpelan mutuamente. Por lo tanto, cuando hablamos de políticas de la memoria no nos referimos solamente a las políticas estatales, sino también a aquellas que diferentes grupos (partidos políticos, organizaciones no gubernamentales, asociaciones sindicales, etc.) despliegan en el 


\section{Memória}

espacio público, en diálogo, discusión y/o imbricación con las primeras. Podemos decir, junto a Escolar (2009), que las políticas de la memoria resultan de la negociación entre diferentes actores de la sociedad política y la sociedad civil y, por esto mismo, constituyen indicadores del estado de las relaciones de fuerza entre los grupos políticos que conforman una sociedad.

Siguiendo a Rabotnikof (2007), definiremos a las políticas de la memoria como las formas de gestionar o lidiar con el pasado (léase, acciones de justicia, institución de fechas y conmemoraciones, políticas de patrimonio, etc.) proyectadas sobre el espacio público y estatal; las cuales emergen, se concretan y transforman a través de distintos "presentes políticos", caracterizados por determinados debates, controversias, acuerdos y desacuerdos sobre cómo abordar el pasado y sobre aquello que puede o no ser narrado (más precisamente, lo que es deseable o no que sea narrado). Es decir, las políticas de la memoria refieren tanto a los proyectos y programas que materializan y gestionan determinadas memorias como también a las luchas políticas en torno a la simbolización del pasado, del presente y del futuro, en el marco de las cuales aquéllos se desarrollan (BESSE y ESCOLAR, 2012). ${ }^{10}$

Debemos decir sin embargo que, de un modo general, estos conflictos por las memorias tienen lugar en el espacio de la política, es decir, el de las voces reconocidas como tales, que narran el pasado y proponen diferentes lecturas, incluso contrapuestas, dentro de un marco común de acontecimientos y procesos que pueden ser pensados, enunciados y recordados en determinado momento. Se trata, en última instancia, de una disputa entre memorias, y entre modos de construcción y transmisión de éstas, que se desenvuelve en lo que Rancière (1996) llama el orden de lo visible, de los lugares habilitados para el disenso y de la cuenta de los que pueden tomar parte en él. Por el contrario, la "batalla" por la memoria adquiere un sentido más radical si se presenta como un movimiento excepcional (BADIOU, 2007), como lo que no estaba previsto, es decir, aquello que viene a establecer un quiebre en el "régimen de memoria" vigente y actualiza

\footnotetext{
${ }^{10}$ En un sentido aún más específico las políticas de la memoria también pueden ser entendidas como políticas de la lengua, es decir, como formas de escritura de la memoria, que pueden reconocerse en distintos géneros discursivos (por ejemplo, en la retórica política; en el discurso de la prensa y otros medios de comunicación; en el saber académico; en la literatura; etc.). En este plano, el conflicto se manifiesta sobre todo entre modos específicos de rememorar, enunciar y dar sentido a los acontecimientos del pasado.
} 


\section{memória}

la distribución de voces, temas y espacios disponibles para la expresión de las memorias conflictivas. ${ }^{11}$ Asistimos, entonces, al momento emergente de lo político, en el cual los que no tenían "la palabra" para hablar del pasado, o mejor dicho, aquellos cuya palabra no era reconocida como tal, se constituyen en sujetos políticos, reclaman para sí un lugar dentro del debate público e inscriben en él sus memorias, otrora inaudibles y subterráneas.

En tanto lo políticos e presenta siempre como desborde, todo intento de la política por retener o establecer un sentido concluyente sobre el pasado, está destinada al fracaso. Es decir que, aún cuando los actores intenten, desde el Estado o las instituciones de la sociedad civil, cristalizar ciertas formas de recuerdo (y ciertas formas de olvido), éstas necesariamente se verán renovadas o transformadas por acción y por efecto de lo político. En todo caso, lo político, y por tanto también la memoria, es un proceso siempre en fuga, aquello que, como "lo real" para Lacan, "no cesa de no inscribirse" (BESSE, 2007).

Recapitulando, en los términos que hemos apuntado la memoria puede ser pensada como práctica política y a la vez como objeto de prácticas políticas. En el primer caso, la memoria "participa" en la lucha hegemónica, como actividad que interviene en el proceso de constitución de agrupamientos políticos, de construcción de sentidos de pertenencia y de legitimación de proyectos políticos en pugna. De esta manera, la memoria puede tanto colaborar en el mantenimiento del orden de la política existente 0 , por el contrario, verse involucrada en una acción colectiva orientada a transformarlo. En el segundo caso, la memoria es el punto de referencia mismo del conflicto político, de disputas entre actores que buscan proyectar en el Estado y en la sociedad determinadas lecturas sobre el pasado. En este caso, la memoria puede ser objeto tanto de pugnas sostenidas en el marco del régimen de memoria vigente, como también de prácticas políticas disruptivas, aquellas que proponen nuevas narrativas y actualizan el repertorio de temas, discusiones y voces autorizadas para hablar del pasado.

\footnotetext{
${ }^{11}$ En una perspectiva foucaultiana, Crenzel utiliza el concepto de régimen de memoria para retratar las memorias que se tornan hegemónicas dentro de la escena pública y en determinado proceso histórico. Sin embargo, aclara, "la propiedad distintiva de un régimen de memoria radica en que sus proposiciones organizan el debate público, se convierten en objeto privilegiado de las luchas por dotar de sentido el pasado, y moldean, e incluso delimitan, las interpretaciones divergentes" (CRENZEL, 2008, p. 25).
} 
Resta decir en todo caso que estas modalidades diferenciadas de articulación entre memoria y política existen como tales sólo a los efectos de análisis. En la práctica, las relaciones se presentan de manera indiferenciada y mutuamente imbricadas. Es por tanto necesario indagar en cada caso y en relación a cada escenario y coyuntura histórica, de qué manera específica se articulan las experiencias de uno y otro campo, cuáles se despliegan dentro del orden de la política y cuáles pueden ser pensadas como emergencias de lo político; qué cambia y qué permanece vigente, qué es lo queda fuera y qué es lo nuevo que se incorpora.

\section{A modo de cierre (o de apertura...)}

Si la memoria se convierte en objeto de la política y de lo político, lo contrario también es cierto. En este sentido, hablar de memorias de la política supone que la política (y lo político) pueda convertirse en objeto de rememoración o algún tipo de trabajo de recuerdo. Para Rabotnikof (2007) esas memorias son tanto los recuerdos del pasado político que construyen aquéllos que fueron contemporáneos a un determinado periodo histórico, como también las imágenes que elaboran las generaciones posteriores a partir de testimonios y documentos, es decir, las "memorias de otras memorias". La relación que mantienen con las políticas de la memoria es que dichas memorias no se despliegan en el vacío sino en el marco de políticas que definen marcos generales de sentido y por tanto influyen en qué se cuenta y qué no se cuenta, es decir, en la selectividad constitutiva de toda memoria. En sentido inverso, las memorias de la política participan en la configuración de políticas de la memoria en tanto y en cuanto instalan en la escena pública determinados recuerdos, significados, debates y controversias sobre el pasado. Sin embargo,es fácil advertir que no todas las memorias de la política logran plasmarse en políticas de la memoria. Es necesario que sobrevengan condiciones sociales y políticas que ofrezcan, primero y ante todo, un marco de escucha posible para esas memorias; condiciones que, por otra parte, los actores (sujetos de esas memorias) contribuyen a crear. 
Tomando por caso el largo proceso de construcción de memorias sobre la violencia estatal ejercida durante la última dictadura militar (1976-1983), que es el tema que nos convoca a pensar las articulaciones entre memoria y política, la conmemoración, en 1996, de los veinte años del último golpe de Estado puede ser interpretada como un momento emergente de lo político, si tenemos en cuenta tanto las memorias divergentes que en ese contexto empiezan a abrir y encontrar un espacio de expresión pública, así como también las nuevas formas de materialización del recuerdo sobre el pasado reciente que emergen a partir de ese momento y que se consolidarán sobre todo a partir de la década siguiente. ${ }^{12}$ En efecto, entre mediados y finales de la década del 90 , comenzaron a tomar estado público las narrativas sobre la militancia política de los años setenta, a través de la publicación de trabajos, fundamentalmente de tipo testimonial, que pusieron en tensión la mirada instituida sobre los desaparecidos como "víctimas inocentes". Asimismo, en un contexto donde la posibilidad de juzgar a los represores se vio obturada por la vigencia de las llamadas Leyes de Impunidad ${ }^{13}$, distintos actores ligados al movimiento de derechos humanos comenzaron a movilizarse en torno a los edificios donde funcionaron centros clandestinos de tortura y desaparición, para exponer públicamente su valor social, como materialidad a preservar para un contexto judicial futuro y como espacios de transmisión de la memoria sobre el terrorismo de Estado (MESSINA, 2010).

Surgidas desde el campo de lo político, esas memorias y modalidades de expresión, establecieron algunas fisuras dentro del régimen de memoria vigente, actualizando el repertorio de temas, voces y espacios para la construcción de las memorias. En efecto, el relato dominante sobre las desapariciones, forjado en los

\footnotetext{
${ }^{12}$ Entre las situaciones que contribuyeron a quebrar el silencio oficial instalado durante los años noventa y a reinstalar el tema en el debate público, debemos sin duda mencionar las confesiones y autocríticas realizadas en 1995 por algunos militares que participaron en la represión y la conmemoración del vigésimo aniversario del golpe militar en 1996. Los cambios que a largo plazo esto produjo en las prácticas y discursos sobre el pasado reciente han sido analizados por diversos autores, véase por ejemplo Valdéz (2001).

${ }^{13}$ Así se conocen popularmente las llamadas leyes de Punto Final (1986) y Obediencia Debida (1987), sancionadas durante el gobierno de Raúl Alfonsín, después de que se condenara a los máximos responsables del terrorismo de Estado durante el Juicio a las Juntas Militares. Ambas tuvieron como objetivo limitar la prosecución jurídica sobre los mandos medios e inferiores de las Fuerzas Armadas y de Seguridad, quienes presionaban al gobierno en esta dirección. Dos años después, el presidente Carlos Menem indultó a los jefes militares condenados en 1985, otorgándoles la libertad. En el 2005 y 2010, respectivamente, las dos leyes y los indultos fueron declarados inconstitucionales por la Corte Suprema de Justicia de la Nación, permitiéndose de este modo la reapertura de las causas suspendidas y la apertura de otras nuevas.
} 


\section{memória}

primeros años de la transición democrática y cristalizado en el informe Nunca Más elaborado en 1984 por la Comisión Nacional sobre la Desaparición de Personas (CONADEP), logró establecer una versión hegemónica del pasado que en lo esencial explicaba, aunque no justificaba, la violencia estatal como consecuencia de la violencia insurgente de los años setenta; presentaba a los desaparecidos como ciudadanos con sus derechos básicos vulnerados, omitiendo toda referencia a sus identidades políticas; y simplificaba la historia política reciente a través de una visión maniquea que permitía evadir la pregunta por las responsabilidades colectivas (CRENZEL, 2008). Dentro de esa matriz de memoria poco espacio hubo para hablar de la militancia política y, en general, de todo aquello que pudiera reavivar los conflictos pasados. El miedo y el horror por las violaciones a los derechos humanos y la necesidad de instaurar una dimensión jurídica en la política, obturaron por mucho tiempo la posibilidad de narrar y revisar las concepciones que habían fundado y alimentado las acciones políticas de los años setenta (SONDERÉGUER, 2001). Sin embargo, como señala Jelin (2013), su ausencia en la narrativa dominante no significó necesariamente su olvido sino más bien su silenciamiento. Los relatos y debates en torno a esas experiencias conformaron durante un largo tiempo lo que Pollak llama memorias subterráneas, aquellas que se sostienen y transmiten desde los márgenes y afloran (o no) en momentos de crisis o efervescencia social. En efecto, fue recién a mediados de los noventa que comenzaron a cobrar mayor visibilidad, aunque mantuvieron una audiencia limitada, las llamadas "memorias militantes" que con sus variantes (desde la exaltación hasta la autocrítica) apuntaban a recuperar las subjetividades políticas y a reconstruir el contexto y el sentido de la acción militante, ya no desde el presente sino desde el pasado (ALTAMIRANO, 2007). ${ }^{14}$ De esta manera, pusieron en tensión la imagen de la víctima pasiva con la cual se había caracterizado hasta entonces a los desaparecidos, desplazando el locus del recuerdo desde el sufrimiento padecido hacia la experiencia política previa.

\footnotetext{
${ }^{14}$ Es posible pensar, señala Vezzetti, que para ese entonces "el fracaso de las promesas nacidas en esa primera experiencia de la democracia haya abierto condiciones [sociales] más receptivas a una recuperación de la tradición revolucionaria" (VEZZETTI, 2009, p. 121, los corchetes son nuestros). Las luchas contra las políticas neoliberales de la década del 90 fueron el marco en el cual comenzaron a aparecer en el discurso de las organizaciones de derechos humanos, principalmente de la Asociación de Madres de Plaza de Mayo, consignas que reivindicaban la militancia social y política (con exclusión de la lucha armada) de los desaparecidos.
} 
Con el tiempo, esas memorias pasaron a configurar una nueva lectura oficial, reivindicativa de la identidad política de los desaparecidos, mientras que la creación de sitios de memoria en ex centros clandestinos se convirtió en una política de Estado. Es decir, hallaron una "expresión programática" en la agenda y el discurso estatal durante los tres gobiernos kirchneristas que se sucedieron entre 2003 y 2015. A tal punto lo hicieron que se convirtieron en un eje central de la política estatal en el área de los derechos humanos y un medio efectivo, entre otros, para la construcción de legitimidad de un proyecto político que encontró adherentes en un amplio sector de la izquierda política identificada con la lucha del movimiento de derechos humanos. Sin embargo, desde muy temprano varios autores (ALTAMIRANO, 2007;CRENZEL, 2008;VEZZETTI, 2009) matizaron el alcance que esa nueva memoria oficial logró en términos de ruptura con la narrativa del Nunca Más, argumentando que, en lo esencial, ésta se mantuvo vigente, revelando aún su potencialidad como vehículo de memoria. Para estos autores, la ausencia de una historización de la violencia política y de un examen complejo de las responsabilidades de los distintos actores dio lugar a una memoria que, desde el ángulo opuesto, ofreció una mirada del pasado políticamente eficaz pero igualmente simplificadora. En ese proceso, la multiplicidad de experiencias y opciones políticas desplegadas durante los años setenta quedó subsumida en la figura genérica de la "militancia popular", la cual permitía ofrecer una imagen heroica (activa) de las víctimas y al mismo tiempo evadir la espinosa cuestión de la lucha armada.

El contexto político actual es muy diferente. Nos encontramos ante un escenario en el cual viejas discusiones retornan al espacio público, motorizadas por una serie de medidas y discursos que emergen en el marco de una nueva conducción estatal. Nos referimos, entre otras cuestiones, a la presentación oficial de una nueva edición del Nunca Más, con la eliminación del prólogo incorporado en el $2006^{15}$; el retorno de las discusiones

\footnotetext{
${ }^{15}$ Al cumplirse en el 2006 el trigésimo aniversario del último golpe de Estado, se publicó una nueva edición del "Nunca Más", con la incorporación de un nuevo prólogo elaborado por la Secretaría de Derechos Humanos de la Nación, a través del cual se discutía, desde una nueva memoria oficial, la relación de causalidad que el prólogo original escrito por la CONADEP establecía entre la violencia insurgente y la estatal. Explicaba, por el contrario, el terror de Estado como un instrumento utilizado por las élites para imponer sistema económico excluyente. Para un análisis sobre los cambios y continuidades entre estas dos lecturas sobre el pasado reciente, véase Crenzel (2008).
} 


\section{Memória}

sobre la cifra total de desaparecidos ${ }^{16}$; las alusiones del presidente en ejercicio a la llamada "guerra sucia" o la re emergencia del debate sobre la violencia política de los años setenta en la prensa y la televisión. En algunos casos se trata de figuras que se revelan anacrónicas ${ }^{17}$; en otros pareciera primar la intención de re instalar en el debate público cuestiones del pasado aún no resueltas. Lo cierto es que, dadas así las cosas, la pregunta por los cambios y continuidades, las rupturas, las vigencias y los alcances sociales de las memorias construidas sobre el pasado reciente, se torna necesario o cuando menos relevante.

\section{Referencias}

ALTAMIRANO, Carlos. Pasado presente. En LIDA, Clara E.; CRESPO, Horacio y YANKELEVICH, Pablo (comps). Argentina 1976, estudios en torno al golpe de Estado. México: ColMex, 2007. pp. 259-284.

BADIOU, Alain. ¿Se puede pensar la política? Buenos Aires: Nueva Visión, 2007

BASTIDE, Roger. Mémoire collective et sociologie du bricolage. In: L’Année sociologique, Nro. 8, pp. 65-108. 1970

BESSE, Juan. Posfacio. Políticas de memoria: usos y desusos. In: BESSE, Juan y KAWABATA, Alejandro (comps.). Grafías del '55. Otros repartos entre recuerdos y olvido. Lanús: EDUNLA, 2007 BESSE, Juan y ESCOLAR, Cora. Política y memoria. Semblanza de una relación indócil. In: Diálogos, Vol. 16, Nro. 2. 2012

\footnotetext{
${ }^{16}$ En lo fundamental el debate sobre la cifra total de desaparecidos durante la dictadura contrapone el número registrado inicialmente por la CONADEP en base a las denuncias formalmente recibidas (más de 8000 ) y el número proyectado por el movimiento de derechos humanos en base a distintas variables (30.000). Más allá de estas discusiones, lo cierto es que, dada la naturaleza del crimen y el silencio sostenido por sus autores, cualquier cifra utilizada será siempre parcial y estará sujeta a futuras actualizaciones.

${ }^{17}$ Nos referimos en este caso a la publicación, en ocasión del 40 aniversario del golpe de Estado, de una nueva edición del "Nunca Más" con su prólogo original en el cual, como hemos visto, el terrorismo de Estado se explicaba como reacción a la violencia insurgente, una perspectiva que no sólo es inexactaen términos históricos sino también anacrónica, dado lo mucho quese ha discutido e investigado sobre el tema. Por un lado, essabido que ni la doctrina ni los métodos utilizados por las fuerzas represivas fueron una reacción, ya que habían sido decididos e incorporadosmucho tiempo antes y que, por otra parte, hacia 1976 la guerrilla ya había sido prácticamente desarticulada (VEZZETTI, 2009).
} 
CASTORIADIS, Cornelius. La Institución Imaginaria de la Sociedad.

Vol. 1. Buenos Aires: Tusquets, 1993

CRENZEL, Emilio. La historia política del Nunca Más. Buenos Aires:

Siglo XXI, 2008

ESCOLAR, Cora. Políticas públicas y memoria. Los observatorios de derechos humanos. In: Revista internacional de ciencias sociales y humanidades (SOCIOTAM), Vol. 19, Nro. 2. 2009

GORDILLO, Ignacio. 2012. La diferencia política-ontológica en la filosofía de Alain Badiou. In: Cuaderno de Materiales, Nro. 24, pp. 6381. 2012.

FELD, Claudia.Trayectorias y desafíos de los estudios sobre memoria en Argentina. In: Cuadernos del IDES, Nro. 32. 2016. pp.4-21.

GROSSBERG, Lawrence. Power and Daily Life. In: We Gotta Get Out of This Place. Popular Conservatism and Postmodern Culture. New York: Routledge, 1992. pp. 89-112.

HALBWACHS, Maurice. La memoria colectiva. Zaragoza: Prensas Universitarias de Zaragoza, 2004.

JELIN, Elizabeth. Los trabajos de la memoria. Madrid: Siglo XXI. 2002. JELIN, Elizabeth. Militantes y combatientes en la historia de las memorias: Silencios, denuncias y reivindicaciones. In: Meridional, Nro. 1. 2013. pp.77-97

LEFORT, Claude. Democracia y advenimiento de un lugar vacío. In: La invención democrática. Buenos Aires: Nueva Visión, 1990. pp. 184193.

MESSINA, Luciana. La construcción de un lugar de memoria: el caso del ex centro clandestino de detención 'Olimpo'. In: Cuadernos del INALP, Nro. 22. 2010.

MOUFFE, Chantal. En torno a lo politico. Buenos Aires: Fondo de Cultura Económica, 2007.

POLLAK, Michael. Memoria, olvido, silencio. La producción social de identidades frente a situaciones límite. La Plata: Al Margen, 2006. 
RABOTNIKOF, Nora. Memoria y política a 30 años del golpe. In: LIDA, Clara E.; CRESPO, Horacio y YANKELEVICH, Pablo (comps). Argentina 1976, estudios en torno al golpe de Estado. México: ColMex, 2007. pp. 259-284.

RAMOS, Ana. Perspectivas antropológicas sobre la memoria en contextos de diversidad y desigualdad. In: Alteridades, Vol. 21, Nro. 42, 2011. pp.131-148.

RANCIÉRE, Jacques. El desacuerdo. Política y filosofía. Buenos Aires: Nueva Visión, 1996.

RANCIÉRE, Jacques. Política, policía, democracia. Santiago de Chile: LOM Ediciones, 2006.

SCHMITT, Carl. El concepto de lo político. Madrid: Alianza Editorial, 2009.

SONDERÉGUER, María. Los relatos sobre el pasado reciente en Argentina: una política de la memoria. In: Iberoamericana, Nro. 1, 2001. pp. 99-112.

TODOROV, Tzvetan. Los abusos de la memoria. Barcelona: Paidós, 2008.

VALDÉZ, Patricia. Tiempo óptimo para la memoria. In: GROPPO, Bruno y FLIER, Patricia. La imposibilidad del olvido: Recorridos de la memoria en Argentina, Chile y Uruguay. La Plata: Al Margen, 2001.

VEZZETTI, Hugo. Sobre la violencia revolucionaria. Memorias y olvidos. Buenos Aires: Siglo XXI, 2009.

* Este artículo fue elaborado en el marco de una investigación financiada con una beca doctoral otorgada por la Universidad de Buenos Aires. 